\title{
Tratamento cirúrgico e reconstrutivo de lesão central de células gigantes em
}

\section{mandíbula: Relato de caso}

\author{
Surgical and reconstructive treatment of central giant cell lesion in the mandible: Case report \\ Tratamiento quirúrgico y reconstructiva de la lesión central de células gigantes en la mandíbula: \\ Relato de caso
}

Recebido: 17/07/2021 | Revisado: 23/07/2021 | Aceito: 24/07/2021 | Publicado: 01/08/2021

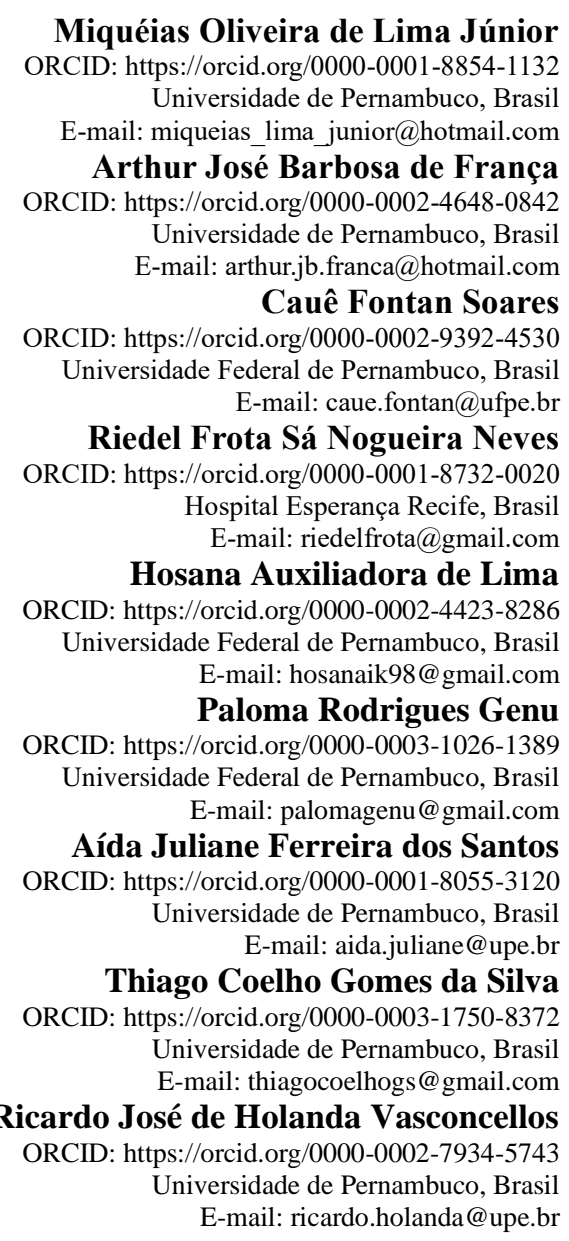

\section{Resumo}

Introdução: A lesão central de células gigantes, também conhecida como granuloma central de células gigantes é considerada como sendo uma lesão não neoplásica, que é constituída por tecido fibroso com focos múltiplos de hemorragia, agregação de células gigantes multinucleadas e, em alguns casos, trabéculas de tecido ósseo, acomete frequentemente a região central da mandíbula, cruzando a linha média, e corresponde a $7 \%$ de todas as lesões benignas dos maxilares. Embora possa afetar uma grande faixa etária, é mais comum de se observar em pacientes entre 2 e 30 anos de idade. Possui uma leve preferência pelo sexo feminino, com um pico de incidência na faixa etária entre 10 e 25 anos. Objetivo: Relatar o caso clínico, bem como discutir a abordagem terapêutica utilizada, de uma lesão central de células gigantes em mandíbula, que progrediu com piora após tratamento conservador proposto. Discussão: O tratamento das LCCG se dá tradicionalmente por remoções cirúrgicas seguidas ou não de curetagem. Há também medidas suplementares, como a criocirurgia ou osteotomia periférica. Em casos onde grandes mutilações são previsíveis, é possível lançar mão de tratamentos alternativos, como as injeções intralesional de corticosteroides, calcitonina, subcutânea ou nasal, interferon al fa- $2^{a}$ subcutânea, imatinib e bifosfonatos. Considerações finais: O tratamento cirúrgico com ressecção parcial associada a reconstrução óssea com osso autógeno de crista ilíaca, se mostrou eficiente em casos de insucesso da terapêutica conservadora.

Palavras-chave: Doenças mandibulares; Doenças ósseas; Granuloma de células gigantes. 


\begin{abstract}
Introduction: The central giant cell lesion, also known as central giant cell granuloma, is considered to be a nonneoplastic lesion, which consists of fibrous tissue with multiple foci of hemorrhage, aggregation of multinucleated giant cells and, in some cases, trabeculae of bone tissue, it frequently affects the central region of the mandible, crossing the midline, and corresponds to $7 \%$ of all benign lesions of the jaws. Although it can affect a wide age group, it is more common to be seen in patients between 2 and 30 years of age. It has a slight preference for the female sex, with an incidence peak in the age group between 10 and 25 years. Objective: To report the clinical case, as well as discuss the therapeutic approach used, of a central giant cell lesion in the mandible, which worsened after the proposed conservative treatment. Discussion: The treatment of LCCG is traditionally by surgical removal followed or not by curettage. There are also supplementary measures such as cryosurgery or peripheral osteotomy. In cases where major mutilations are predictable, alternative treatments can be used, such as intralesional injections of corticosteroids, calcitonin, subcutaneous or nasal, subcutaneous alpha-2a interferon, imatinib and bisphosphonates. Final considerations: Surgical treatment with partial resection associated with bone reconstruction with autogenous iliac crest bone proved to be efficient in cases of failure of conservative therapy.
\end{abstract}

Keywords: Disease mandibular; Bone diseases; Granuloma, giant cell.

\title{
Resumen
}

Introducción: La lesión central de células gigantes, también conocida como granuloma central de células gigantes, se considera una lesión no neoplásica, que consiste en tejido fibroso con múltiples focos de hemorragia, agregación de células gigantes multinucleadas y, en algunos casos, trabéculas de tejido óseo, afecta frecuentemente a la región central de la mandíbula, cruzando la línea media, y corresponde al 7\% de todas las lesiones benignas de los maxilares. Aunque puede afectar a un amplio rango de edad, es más común observarlo en pacientes entre 2 y 30 años. Tiene una ligera preferencia por el sexo femenino, con un pico de incidencia en el grupo de edad entre 10 y 25 años. Objetivo: Reportar el caso clínico, así como discutir el abordaje terapéutico utilizado, de una lesión central de células gigantes en la mandíbula, que empeoró tras el tratamiento conservador propuesto. Discusión: El tratamiento del LCCG es tradicionalmente mediante extirpación quirúrgica seguida o no de legrado. También existen medidas complementarias como la criocirugía u osteotomía periférica. En los casos en que sean predecibles mutilaciones importantes, se pueden utilizar tratamientos alternativos, como inyecciones intralesionales de corticosteroides, calcitonina, interferón alfa-2a subcutáneo o nasal, subcutáneo, imatinib y bisfosfonatos. Consideraciones finales: El tratamiento quirúrgico con resección parcial asociado a la reconstrucción ósea con hueso autógeno de la cresta ilíaca demostró ser eficaz en los casos de fracaso de la terapia conservadora.

Palabras clave: Enfermedades mandibulares; Enfermedades óseas; Granuloma de células gigantes.

\section{Introdução}

A lesão de células gigantes se diferencia como lesão central, quando é endosteal, ou periférica, quando envolve o periósteo (Spini et al., 2019). A lesão central de células gigantes, também conhecida como granuloma central de células gigantes é considerada como sendo uma lesão não neoplásica (Neville et al., 2009), que é constituída por tecido fibroso com focos múltiplos de hemorragia, agregação de células gigantes multinucleadas e, em alguns casos, trabéculas de tecido ósseo (Bocchialini et al., 2019; Loureiro et al., 2019; Tecco et al., 2018).

Sendo descrita como lesão intraóssea benigna (Bocchialini et al., 2019) e classificada como não odontogênica, pode apresentar comportamento agressivo similar a uma neoplasia em razão de sua grande proliferação no número celular (Lima et al., 2019). Embora inicialmente denominada como um granuloma reparador de células gigantes, há pouca evidência de que a lesão represente uma resposta de reparo, fazendo com que este termo não seja frequentemente utilizado (Neville et al., 2009). A etiologia dessa lesão é desconhecida podendo estar relacionada a trauma, focos inflamatórios ou predisposição genética (Wang et al., 2019).

A lesão central de células gigantes acomete frequentemente a região central da mandíbula, cruzando a linha média, e corresponde a 7\% de todas as lesões benignas dos maxilares (Lima et al., 2019; Loureiro et al., 2019; Tecco et al., 2018; Wang et al., 2019). Embora possa afetar uma grande faixa etária, é mais comum de se observar em pacientes entre 2 e 30 anos de idade (Loureiro et al., 2019; Neville et al., 2009). Possui uma leve preferência pelo sexo feminino, com um pico de incidência na faixa etária entre 10 e 25 anos (Wang et al., 2019).

Frequentemente assintomática, essa lesão pode chamar a atenção inicialmente durante um exame radiográfico de rotina 
como consequência de expansão indolor do osso afetado. No entanto, uma pequena quantidade de casos pode apresentar sintomatologia dolorosa, perfuração da tábua óssea cortical ou parestesia, podendo ocasionar ulceração da superfície da mucosa pela lesão subjacente (Neville et al., 2009). Radiograficamente, as lesões centrais de células gigantes aparecem como lesões radiolúcidas, uni ou multiloculares, com bordas bem definidas (Orzechowski et al., 2012).

Lesões centrais de células gigantes podem ser divididas em dois subtipos, agressivo e não agressivo, sendo o subtipo agressivo mais comum, apresentando-se como uma lesão indolor de crescimento lento com expansão do osso cortical (Wang et al., 2019).

Nesse contexto, o objetivo do presente trabalho é relatar o caso clínico, bem como discutir a abordagem terapêutica utilizada, de uma lesão central de células gigantes em mandíbula, que progrediu com piora após tratamento conservador proposto.

\section{Metodologia}

Trata-se de um estudo observacional descritivo de relato de caso. Como complemento do estudo, foi realizado uma revisão da literatura por meio da pesquisa de artigos científicos dos últimos 12 anos na base de dados MEDLINE através do portal PubMed e Lilacs, onde foram escolhidos àqueles semelhantes ao caso descrito para compor a discussão do estudo. Por se tratar de um Relato de Caso Clínico, não houve necessidade de aprovação pelo Comitê de Ética em Pesquisa da instituição. O relato do caso foi autorizado pelo paciente através da assinatura do Termo de Consentimento Livre e Esclarecido (TCLE).

\section{Relato de Caso}

Paciente do gênero feminino, 28 anos, admitida no serviço de Cirurgia e Traumatologia Bucomaxilofacial do Hospital Getúlio Vargas há cerca de cinco anos, com histórico de dor em mandíbula sem achados clínicos compatíveis. Através do exame de imagem constatou-se lesão multilocular, envolvendo a região de corpo mandibular direito, se estendendo da região do dente 45 ao 47, com cerca de $4 \mathrm{~cm}$ de diâmetro, e causando reabsorção dentária dos dentes 46 e 47, que também apresentavam pequena mobilidade e perda de vitalidade.

A Figura 1 apresenta uma radiografia panorâmica dos maxilares, realizada no primeiro contato com a paciente para elucidação das queixas.

Figura1. Radiografia panorâmica dos maxilares.

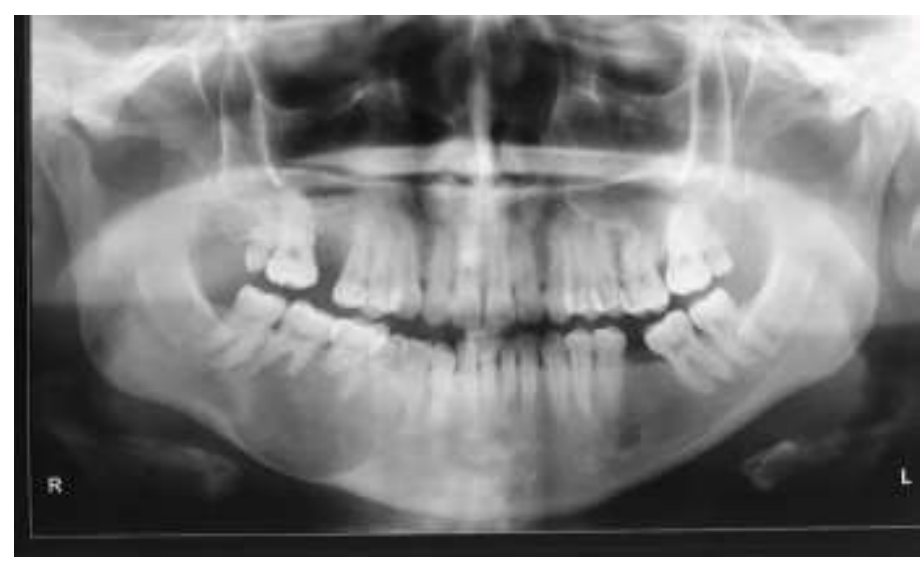

Fonte: Autores.

O diagnóstico presuntivo foi de Ameloblastoma, sendo confirmado através de estudo anatomopatológico após biópsia incisional realizada no serviço, o laudo de Lesão Central de Células Gigantes (LCCG). Como conduta, foram realizadas terapias conservadoras com injeções intralesionais de corticosteroides (calcitonina) sem sucesso, ocorrendo aumento da lesão. O 
Research, Society and Development, v. 10, n. 9, e51610918350, 2021

(CC BY 4.0) | ISSN 2525-3409 | DOI: http://dx.doi.org/10.33448/rsd-v10i9.18350

tratamento curativo proposto consistiu em ressecção mandibular parcial com margens de segurança que se excediam os 5 mm, através de acesso intra-oral e instalação de placa de reconstrução do sistema 2.4.

A Figura 2 demonstra o planejamento pré-operatório, com uso de biomodelos e pré-modelagem da placa de reconstrução do sistema 2.4 Locking.

Figura 2. Biomodelos para planejamento cirúrgico. A) Delimitação da lesão. B) Pré- modelagem da placa de reconstrução.

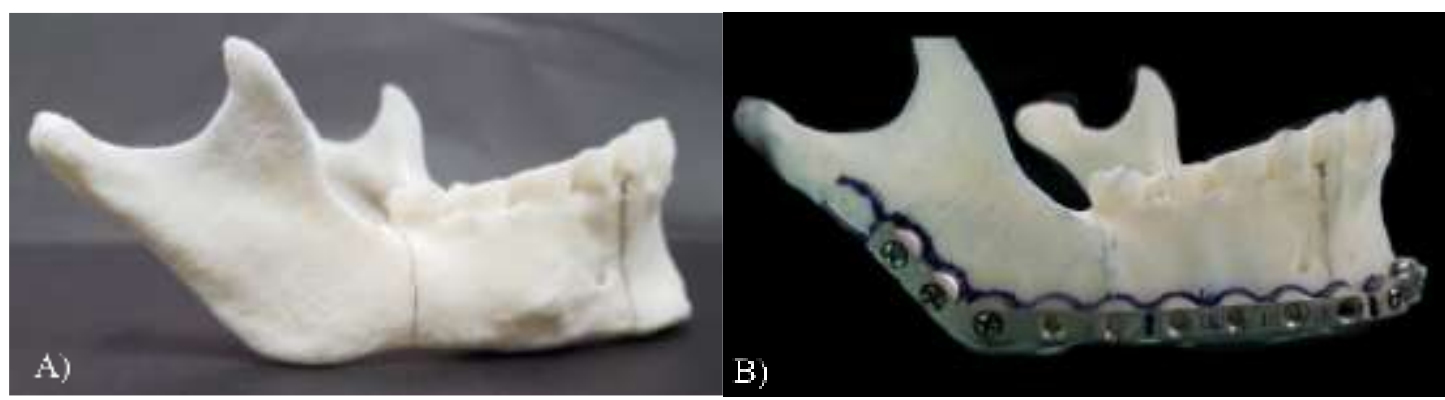

Fonte: Autores.

A Figura 3 representa a etapa cirúrgica inicial, que consistiu na remoção da lesão com margens de segurança, através de acesso intraoral. 
Figura 3. Etapa cirúrgica inicial. A) Aspecto intraoral antes da intervenção. B) Acesso vestibular mandibular e exposição da lesão. C) Foi realizado instalação da placa de reconstrução após uma osteoplastia de mandíbula e a demarcação da área a ser removida com auxílio de brocas cirúrgicas. D) Peça cirúrgica após a ressecção parcial da mandíbula.

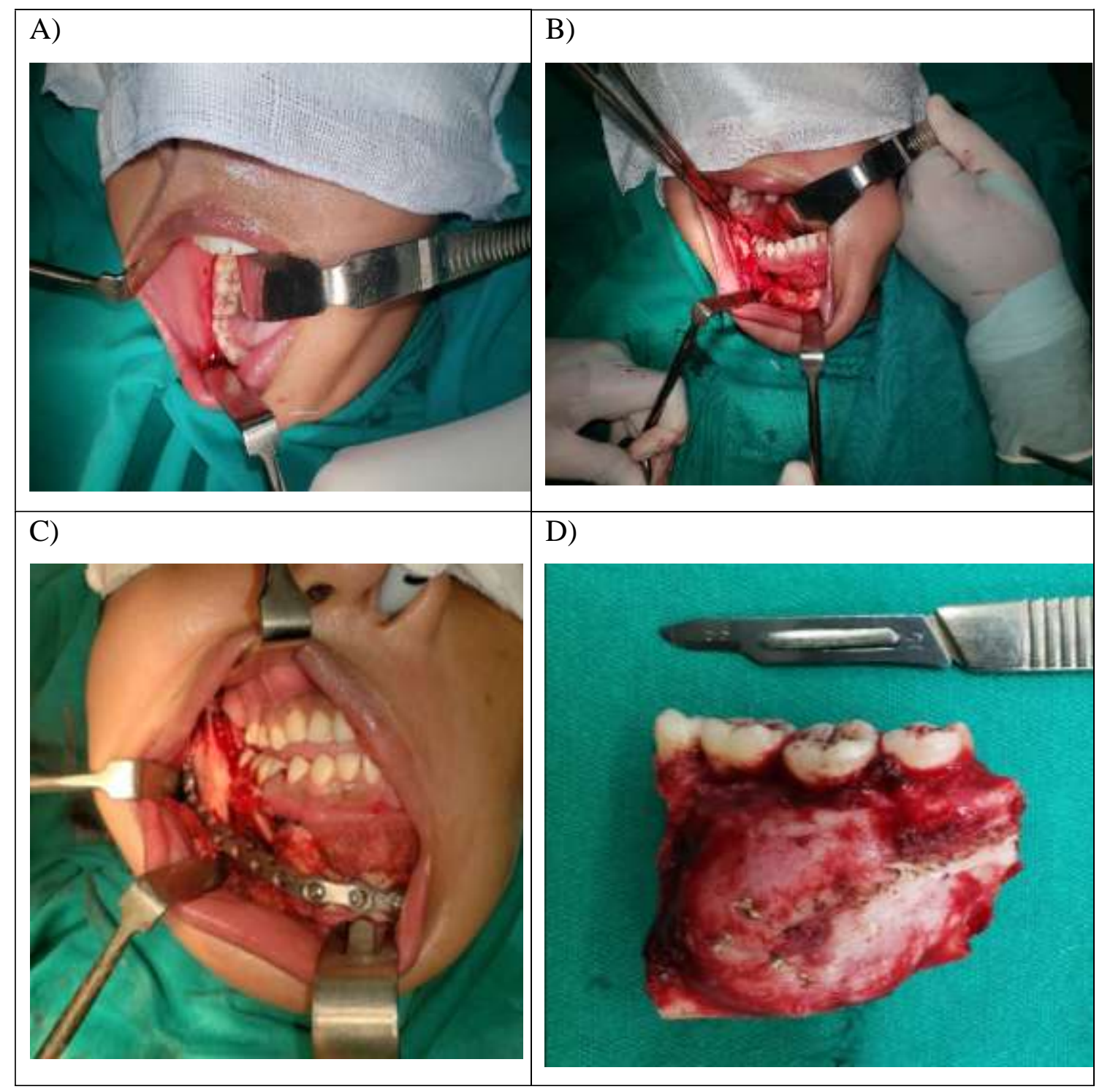

Fonte: Autores.

Após 3 meses programou-se a cirurgia reconstrutiva, na qual optou-se por enxerto autógeno de crista ilíaca, adaptado a placa previamente instalada. 
Figura 4. Etapa Cirúrgica reconstrutiva. A) Radiografia panorâmica dos maxilares após a primeira intervenção cirúrgica. B) Acesso submandibular (Risdon), para exposição do defeito. C) Mensuração e remoção de osso doador de região Ilíaca. D) Adaptação do osso doador ao defeito e fixado a placa de reconstrução previamente instalada.
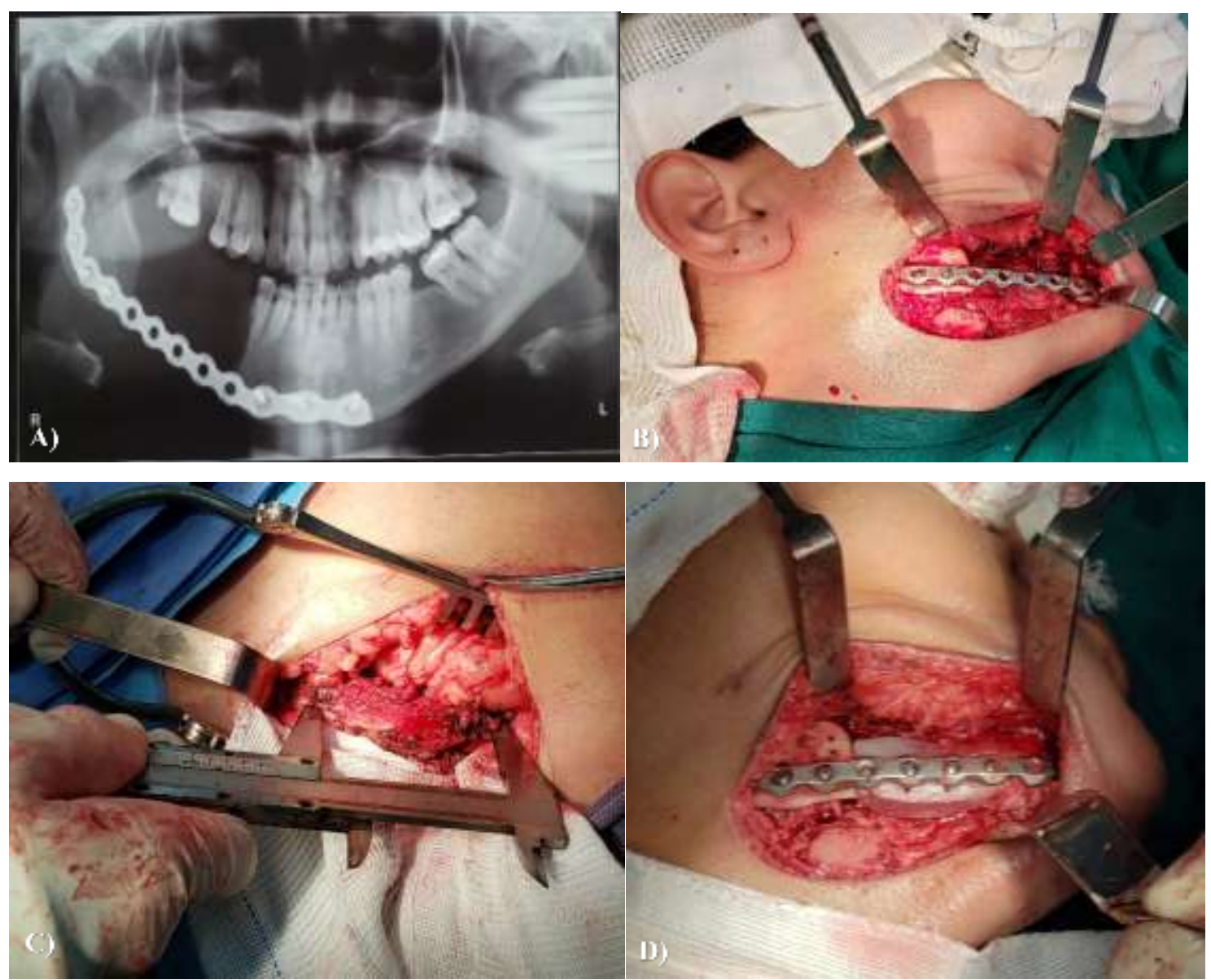

Fonte: Autores.

A paciente segue em acompanhamento por 03 anos, sem queixas ou históricos de recidiva da lesão, aguardando somente a reabilitação por implantes dentários. 
Figura 5. Tomografia computadorizada para controle pós operatório de 03 anos.

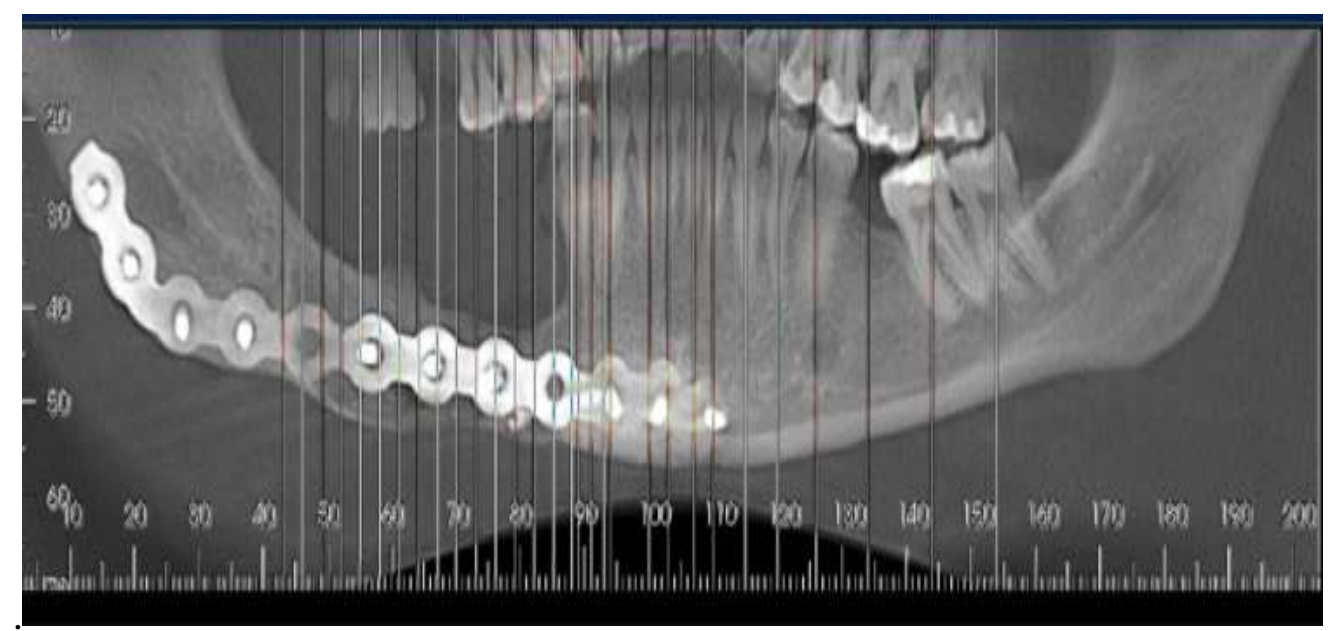

Fonte: Autores.

\section{Discussão}

Lesões centrais de células gigantes ocorrem exclusivamente na cavidade oral (Nagar et al., 2020), com base em suas características clínicas e radiográficas, vários grupos de investigadores têm sugerido que as lesões centrais de células gigantes dos ossos gnáticos podem ser divididas em duas categorias: 1. Lesões não-agressivas, que constituem a maioria dos casos e exibem poucos ou nenhum sintoma, demonstram crescimento lento e não mostram perfuração da cortical ou reabsorção radicular dos dentes envolvidos na lesão; 2. Lesões agressivas são caracterizadas por dor, crescimento rápido, perfuração da cortical e reabsorção radicular. Elas mostram acentuada tendência a recidivar após o tratamento, comparadas com os tipos não-agressivos (Neville et al, 2009; Silva et al, 2018; Zhang; Wang; Jiang, 2019).

As lesões não agressivas compõem a maioria dos casos e se apresentam em tamanho menor. Costumam evoluir de forma assintomática, onde a perfuração óssea e a reabsorção radicular são incomuns. A descoberta se dá através do achado clínico e/ou radiográfico em exames de rotina, ou mediante ao início de expansão óssea indolor. As lesões agressivas são caracterizadas pela sintomatologia dolorosa, crescimento rápido, rompimento da cortical ou reabsorção radicular, que pode acarretar deslocamento dentário e/ou parestesia (Loureiro et al., 2019).

Radiograficamente, as lesões centrais de células gigantes aparecem como defeitos radiolúcidos que podem ser uni ou multiloculares (Ramesh, 2020). O defeito é geralmente bem delimitado, mas as margens comumente são desprovidas de halo radiopaco (Neville et al., 2009). As lesões podem variar de um achado radiográfico incidental de $5 \times 5 \mathrm{~mm}$ a uma lesão destrutiva maior que $10 \mathrm{~cm}$ de tamanho (Loureiro et al., 2019). Os achados radiográficos não são específicos para o diagnóstico. Lesões uniloculares pequenas podem ser confundidas com granulomas periapicais ou cistos. Lesões de células gigantes multiloculares não podem ser distinguidas radiograficamente de ameloblastomas ou outras lesões multiloculares (Neville et al., 2009; Loureiro et al., 2019).

O tratamento das LCCG se dá tradicionalmente por remoções cirúrgicas seguidas ou não de curetagem (Choe et al., 2021). Há também medidas suplementares, como a criocirurgia ou osteotomia periférica. Em casos onde grandes mutilações são previsíveis, é possível lançar mão de tratamentos alternativos. Dentre os tratamentos alternativos estão as injeções intralesional de corticosteróides, calcitonina, subcutânea ou nasal, interferon al fa-2a subcutânea, imatinib e bifosfonatos (Neville et al., 2016). A LCCG é uma lesão relativamente incomum e apresenta desafios em seu diagnóstico (Loureiro et al., 2019).

A calcitonina é um hormônio influente na remodelação óssea e a terapêutica via uso nasal ou subcutânea vem sendo estudada, principalmente, em quadros clínicos de distúrbios da tiroide, a fim de evitar que pacientes candidatos a tireoidectomia 
sofram de osteopenia (Orzechowski et al., 2012). O interferon alfa-2a é um fármaco antiangiogênico ainda em estudo, pois observou-se que atua na inibição e/ou regressão de tumores que dependem da angiogênese para seu crescimento e metastização (Orzechowski et al., 2012).

O diagnóstico diferencial da LCCG é feito, geralmente, com o tumor marrom do hiperparatireoidismo, o querubismo e o cisto aneurismático, entre outros (Lima et al., 2019). No caso do tumor marrom do hiperparatireoidismo a suspeita deve ser eliminada através de exames de cálcio, fosfato e paratormônio (Mohan et al., 2013). Em relação ao querubismo, que se caracteriza por uma expansão bilateral de maxila ou mandíbula e torna-se evidente nos primeiros anos de vida, a diferenciação deve ser realizada por meio de uma criteriosa anamnese, seguida de exame clínico e radiográfico, já que histologicamente são indistinguíveis (Lima et al., 2019). O desenvolvimento da LCCG e do querubismo são possivelmente mediados por uma sobreexpressão do TNF $\alpha$ (Fator de Necrose Tumoral alfa) no núcleo das células multinucleares. Já o cisto ósseo aneurismático é caracteristicamente composto por fibroblastos, células gigantes e trabéculas de aspecto osteoide embebidas num estroma muito parecido com a LCCG. Para o estabelecimento do diagnóstico diferencial, deve-se saber que sua etiologia está ligada a história de trauma ou alterações hemodinâmicas locais em crianças e adolescentes (Orzechowski et al., 2012).

A LCCG também pode estar associado a outras lesões intrabucais de origem genética, como na neurofibromatose tipo 120 e na Síndrome de Kartagener, uma condição grave de comprometimento do trato respiratório superior e inferior (Orzechowski et al., 2012).

A análise histopatológica é considerada como método fundamental de diagnóstico (Gupta et al., 2013), mesmo outras patologias, como cisto ósseo aneurismático, tumor marrom de hiperparatireoidismo, TCG e querubismo, tendo características histopatológicas semelhantes (Loureiro et al., 2019). Por isso é importante a associação dos aspectos clínicos e histológicos para fechamento do diagnóstico, e ainda se possível ter uma ideia do curso da lesão (Lima et al., 2019).

Histopatologicamente, as LCCG variam de poucas a muitas células gigantes multinucleadas em estroma mononuclear de células ovóides a fusiformes (Chrcanovic; Gomes; Gomez, 2018; Melo-Muniz et al., 2020). É comum também observar em diferentes pontos da lesão, a presença de osso neoformado e a formação de osteóide. A forma agressiva e a não agressiva exibem características microscópicas semelhantes, embora as lesões agressivas estejam correlacionadas com células gigantes maiores (Loureiro et al., 2019; Spini et al., 2019).

A ressecção em bloco, tratamento preconizado para tumores mais agressivos e recorrentes, ocasiona grandes defeitos faciais e perda de elementos dentários, o que particularmente é multilante em crianças e adultos jovens. Uma extensa reconstrução, nesses casos, é necessária para restabelecer a função e a anatomia (Silva et al., 2018). Os sítios doadores de enxertos autógenos considerados como padrão ouro são a crista ilíaca, fíbula, costelas e calota craniana. O uso desses enxertos tem propriedades osteogênicas (Barbosa et al., 2019).

Os enxertos utilizados nas reconstruções mandibulares podem ser livres, quando se constituem apenas de tecido ósseo, ou microvascularizados, quando possuem uma vascularização adicional associada a um pedículo de tecido mole que albergue vasos que serão anastomosados com os vasos faciais. O enxerto ósseo livre, por outro lado, necessita de uma revascularização proveniente dos tecidos circundantes à área reconstruída, quanto à utilização do enxerto livre não vascularizado a taxa de insucesso se eleva com o aumento do comprimento do defeito. Há falha em 17\% para defeitos de $6 \mathrm{~cm}$ e falha de $75 \%$ para defeitos com $12 \mathrm{~cm}$ ou mais (Pirgousis et al., 2013). Outros autores, como por exemplo (Vayavada et al., 2006), afirmam que só em áreas maiores de $7 \mathrm{~cm}$, prefere-se a realização de retalhos microvascularizados, visto que os enxertos ósseos convencionais têm alto índice de complicações nesses casos (Vayavada et al., 2006). Os estudos descritos acima, vão de encontro ao caso estudado, onde obteve-se sucesso com enxerto não vascularizado de ilíaco com $5 \mathrm{~cm}$ de comprimento. 


\section{Conclusão}

Vários tratamentos propostos para as lesões centrais de células gigantes são discutidos na literatura, bem como a necessidade ou não de abordagens complementares. A escolha do tratamento está subordinada a diversos fatores, dentre eles a natureza agressiva e invasiva da lesão, o local, o tamanho e sua relação com estruturas anatômicas importantes, o insucesso ao tratamento conservador empregado. A partir disso, pode-se avaliar que tipos de abordagens estão indicadas, sendo conservadoras ou radicais, visando a manutenção de estruturas importantes, a redução da lesão e diminuir os riscos de recidivas.

O tratamento deve sempre visar a função mastigatória do paciente, principalmente quando a lesão acomete a região dentária, nesse caso, o enxerto autógeno não vascularizado de crista ilíaca se mostrou eficaz permitindo a etapa reabilitadora com implantes dentários.

\section{Referências}

Spini, R., Juchli, M., Fernández, M., \& Ramírez, Z. (2019). Granuloma gigantocelular de mandíbula en un niño de 6 años de edad: Reporte de un caso. Arch. argent. pediatr, 173-177.

Neville, B. (2009). Patologia oral e maxilofacial. Elsevier Brasil.

Bocchialini, G., Salvagni, L., Guerini, A., \& Castellani, A. (2020). Central giant cell granuloma of the mandibular condyle: A rare case and a literature review. Heliyon, 6(1), e03085.

Loureiro, A. M. L. C., da Silva, C. L., de Oliveira Nunes, L. S., Theotonio, P. E. S., Santana, S. F., de Melo Franco, Á. V., \& de Carvalho Nogueira, P. T. B. (2019). Abordagem farmacológica em lesão central de células gigantes: Relato de caso. Revista Eletrônica Acervo Saúde, (37), e2111-e2111.

Tecco, S., Caruso, S., Nota, A., Leocata, P., Cipollone, G., Gatto, R., \& Cutilli, T. (2018). Bilateral Central Giant Cell Granuloma of the mandibular angle in three females from the same family. Head \& face medicine, 14(1), 14.

Lima, E. C. G., Cardoso, M. S., Barbosa, G. M., de Souza Neto, F. J., da Silva, B. B. P., Xavier, T. B., \& Pontes, H. A. R. (2019). Tratamento de lesão central de células gigantes Recidivante: relato de caso/Giant cell central injury treatment Relapse: case report. Brazilian Journal of Health Review, 2(6), $5382-5395$.

Wang, Y., Le, A., El Demellawy, D., Shago, M., Odell, M., \& Johnson-Obaseki, S. (2019). An aggressive central giant cell granuloma in a pediatric patient: case report and review of literature. Journal of Otolaryngology-Head \& Neck Surgery, 48(1), 32.

Orzechowski, P. R., Takashima, M., Romeiro, R. D. L., Santana, J. B., \& Campos, M. S. (2012). Granuloma Central de Células Gigantes: Relato de Caso Clínico. Revista de Cirurgia e Traumatologia Buco-maxilo-facial, 12(4), 61-68.

Nagar, S. R., Bansal, S., Jashnani, K., Sinha, A., \& Desai, R. S. (2020). A Comparative Analysis of p63 Expression in Giant Cell Tumour (GCT), Central Giant Cell Granuloma (CGCG) and Peripheral Giant Cell Granuloma (PGCG). Head and neck pathology, 14(3), 733-741.

Silva, W. S., Moreira, G., Marques, I. P., \& Silva, Â. F. (2019). Lesão Central de Células Gigantes-Relato de Caso. Revista Eletrônica Acervo Saúde, (17), e192-e192.

Zhang, Q., He, Z., Wang, G., \& Jiang, H. (2019). Radiotherapy for recurrent central Giant cell granuloma: a case report. Radiation oncology (London, England), $14(1), 130$.

Ramesh V. (2020). "Central giant cell granuloma" - An update. Journal of oral and maxillofacial pathology : JOMFP, 24(3), 413-415.

Choe, M., Smith, V., Okcu, M. F., Wulff, J., Gruner, S., Huisman, T., \& Venkatramani, R. (2021). Treatment of central giant cell granuloma in children with denosumab. Pediatric blood \& cancer, 68(3), e28778.

Mohan, R. P., Verma, S., Agarwal, N., \& Singh, U. (2013). Central giant cell granuloma: a case report. BMJ case reports, 2013 , bcr2013009903.

Gupta, M., Gupta, M., Singh, S., \& Kaur, R. (2013). Central giant cell granuloma of the maxilla. BMJ case reports, 2013 , bcr2013009102.

Chrcanovic, B. R., Gomes, C. C., \& Gomez, R. S. (2018). Central giant cell lesion of the jaws: An updated analysis of 2270 cases reported in the literature. Journal of oral pathology \& medicine: official publication of the International Association of Oral Pathologists and the American Academy of Oral Pathology, 47(8), 731-739.

Melo-Muniz, V., Nunes, F. D., Cangussu, M., Cury, P. R., Xavier, F., de Azevedo, R. A., Leitão, Á., de Faro Valverde, L., Carneiro Júnior, B., \& Dos Santos, J. N. (2020). Central giant cell granuloma: A clinicopathological and immunohistochemical study of macrophages, blood vessels, lymphatic vessels and regulatory proteins. Annals of diagnostic pathology, 46, 151526.

Barbosa, C. D. S. (2019). Reconstrução óssea com enxerto autógeno de crista ilíaca em fratura cominutiva de mandíbula PAF: relato de caso.

Pirgousis P; Brown D; L Fernandes. Digital Measurementes of 120 mandibular Angles to determine the ideal Fibula Wedge Osteotomy To Re-Create. The Mandibular Angle For Microvascular Reconstruction. Jornal Maxillofac Surg 71:2169-2175,2013.

Vayvada H, Mola F, Menderes A, et al.Surgical management of ameloblastoma in the mandible: Segmental mandibulectomy and immediate reconstruction with free fibula or deep circumflex iliac artery flap (evaluation of the long-term esthetic and functional results). J Oral MaxillofacSurg, 2006 ; 64:1532. 